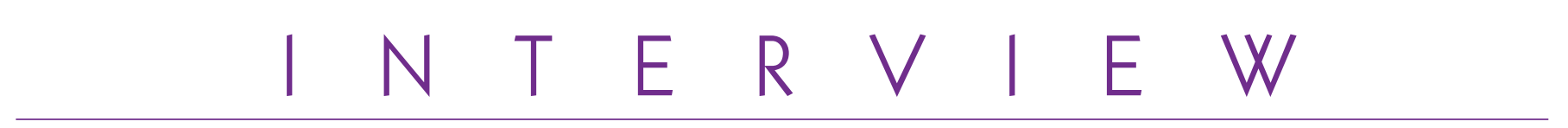

\title{
Interview with Prof D.E. Lieberman
}

\author{
M. Makaremi
}

Qualified Specialist in Dental and Facial Orthopedics, Private Practice, Researcher in Anthropology

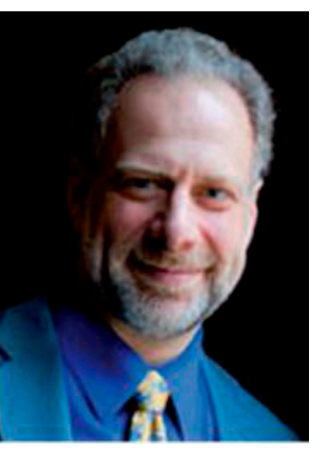

\section{INTRODUCTION}

Professor Lieberman is director of the Department of Human Evolution and the Osteology Laboratory at Harvard University. $\mathrm{He}$ is the author of many papers published in the most prestigious journals. His work has given us a better understanding of the evolutionary path that forged the anatomy of modern human beings. His research focuses on the specificity of our cranial morphology and our evolutionary adaptation over the course of our long history. As a prelude to this issue, it seemed relevant to broaden our horizons by addressing some of the fundamental issues common to both disciplines: orthodontics and anthropology.

\section{In your last book, you suggest a dose of evolution in medicine: Can you explain this to the reader?}

Our body is the result of evolution. It was not designed by engineers. Everything has evolved: the way we breathe, what we eat, how we think. Every aspect of our biology is part of the history of our evolution. For each generation, the human body reflects on this process, assessing the environment in which it lives. To understand the body as it is, and the reason for our illnesses, we must take into consideration the principle of evolution.

Most diseases are the result of adapting our body to our environment. Yet our world has changed dramatically. We believe that the world we live in is normal. From the perspective of evolution, it is not. It is not normal to eat processed foods that are full of sugar and lacking in fiber. It is not normal to eat food without consistency that comes out of a box. It is not normal to drive cars and sit on chairs. Evolution explains why things are the way they are, why we have serious malocclusions, why we have

Address for correspondence:

Masrour Makaremi - 2 rue des Deux Conils

24100 Bergerac - France

E-mail: makaremi.orthodontie@gmail.com

Article received: 28-09-2014. Accepted for publication: 17-11-2014.

This is an Open Access article distributed under the terms of the Creative Commons Attribution License (http://creativecommons.org/licenses/by/4.0), which permits unrestricted use, distribution, and reproduction in any medium, provided the original work is properly cited. 
cavities, and why we have cancers and heart disease. We will not find an answer to any of these questions without taking evolution into account.

\section{How do you look at the increase in craniofacial dysmorphia since the Industrial Revolution?}

If we think there are more dysmorphia cases, we have to ask why. I do not think it has anything to do with the ethnic composition of the population. Approximately $82 \%$ of the cranial variations that exist are present in all populations around the globe. What has actually changed over time is not our genes, but our environment. Before, everyone was a hunter/gatherer. Now our food is industrial. Therefore, people chew less and therefore do not need to exert as much force when chewing. As a result, our diet has had an effect on facial development. The prevalence of malocclusions is much less common in human skulls found in archeological research, and it is the same with myopia. I think a lot of craniofacial dysmorphia cases are recent problems.

\section{Your work and those of different authors have shown that the structure of the chin is unique to Homo sapiens. How can we explain this distinctive feature?}

The chin is unique to the anatomy of modern humans. There is no consensus on the basis of this phenomenon: some think it is because of language, others to chewing. In my opinion, these assumptions are weak, because our ancestors had very difficult diets and they did not need a chin. Following another theory, the chin appeared when our skulls shrunk. A final hypothesis is down to sexual selection because we do not like people who do not have a chin, but the latter is impossible to prove. From a developmental perspective, we cannot answer this question in a functional way.

To what extent does the skull base influence the appearance of facial dysmorphia?

The skull is a very complex structure. We know that the skull base will have an effect on facial dysmorphia, a significant but not determinative effect, and there will never be a simple answer.

\section{Do you think that our morphological adaptation over the course of our history has affected the development of our face?}

Humans have indeed evolved to run. There are morphological adaptations that have occurred in the head and neck region. The nose may be a part of it: we use our nose to cool down (it is a part of our thermoregulatory apparatus). When human ancestors had to deal with a hot environment, nose development was necessary.

\section{What senses have contributed the dental structure of primates remaining the same for 25 million years (the same structure is found in all primates)?}

Within the evolutionary process, many things do not change. We have, like most animals, five fingers. Natural selection leads to hereditary variation, a positive or negative adaptation. We can therefore assume that the increase or reduction in the number of molars, premolars, or incisors is not particularly interesting because these have not changed. In many ways, our bodies resemble that of other primates. We are more than 90\% genetically identical to chimpanzees. 
How can we explain that very important alveolar compensations exist naturally and in many species (e.g., rock hyrax)? Whereas they are so unstable in humans, when produced by therapeutics, that they require the extraction of premolars...

We need to integrate everything to make sure it all works. A tooth, to stay in a stable position all its life, needs to be strong. Chewing forces help to ensure that the teeth fit properly. This is the result of a primitive adaptation, common to all beings. However, nowadays, humans do not chew food that is hard enough for the teeth. Therefore, there are more cases of malocclusions in humans than in any other species.

As I told you, the world we live in is not normal. Orthodontists remove premolars to create space because our heads are smaller. They are smaller because we chew softer foods. So, we rely on the dental structure which we have inherited from our ancestors.

Interview conducted and translated by Dr. Makaremi

Conflict of interest: The author declares that there is no conflict of interest.

\section{WORKS TO CONSULT}

\section{Books}

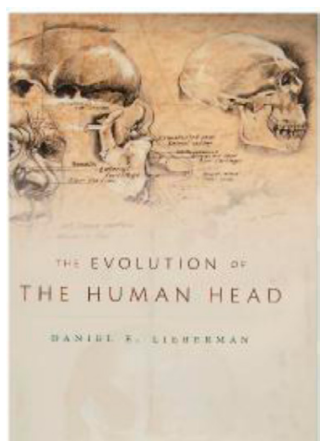

Lieberman D.E. (2013) The Story of the Human Body: Evolution, Health and Disease. New York: Pantheon Press.

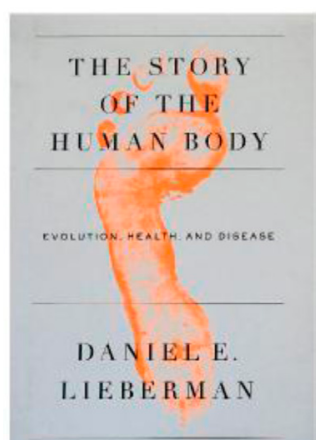

Lieberman D.E. (2011) The Evolution of the Human Head. Cambridge, MA: Harvard University Press. 


\section{ARTICLES (SELECTION)}

1. Bramble D.M., Lieberman D.E. (2004) Endurance Running and the Evolution of Homo. Nature 432:345-352.

2. Eng C.M., Lieberman D.E., Zink K.D., Peters M.A. (2013) Bite force and occlusal stress production in hominin evolution. Am J Phys Anthropol 151:544-57.

3. Lieberman D.E. (2012) Those feet in ancient times. Nature 483:550-1.

4. Lieberman D.E. (2005) Sexual and geographic varia-tion in the skull. Gray's Anatomy, 39th Ed. Edinburgh: Elsevier.

5. Lieberman D.E., Krovitz G., Devlin M., Yates F., St. Clair M. (2004) Effects of food processing on masti-catory strain and craniofacial growth in a retrognathic face. Journal of Human Evolution 46:655-677.

6. Lieberman D.E., McBratney B.M, Krovitz G.E. (2002) The evolution and development of craniofacial form in Homo sapiens. Proceedings of the National Academy of Sciences 99:1134-1139.

7. Lieberman D.E., Crompton A.W. (2000) Why fuse the mandibular symphysis? A comparative analysis. American Journal of Physical Anthropology 112:517-540.

8. Lieberman D.E., Mowbray K.M., Pearson O.M. (2000) Basicranial influences on overall cranial shape. Journal of Human Evolution 38:291-315.

9. Lieberman D.E. (1998) Sphenoid shortening and the evolution of modern human cranial shape. Nature 393:158-162. 